\title{
Developmental Changes in Proximal Tubule Tight Junction Proteins
}

\author{
MAHA HADDAD, FANGMING LIN, VANGIPURAM DWARAKANATH, \\ KIMBERLY CORDES, AND MICHEL BAUM
}

Departments of Pediatrics [M.H., F.L., V.D., K.C., M.B.] and Internal Medicine [M.B.], University of

Texas Southwestern Medical Center at Dallas, Dallas, TX 75235

\begin{abstract}
We demonstrated previously that neonatal proximal tubules have a lower passive paracellular permeability to chloride ions and higher resistance than that of adult proximal tubules. In addition, administration of thyroid hormone to neonates, before the normal maturational increase in serum thyroid hormone levels, prematurely accelerates the developmental increase in chloride permeability to adult levels. To test the hypothesis that there is a maturational change in tight junction proteins and that thyroid hormone mediates these changes, we examined the two known tight junction proteins present in proximal tubules, occludin and claudin 2 . Using immunoblot and immunohistochemistry, we demonstrated that claudin 2 has a 4-fold greater abundance in neonatal proximal tubules than in adult tubules.
\end{abstract}

ABSTRACT

Occludin, however, has a 4-fold greater expression in adult tubules than in neonatal tubules. Administration of thyroid hormone to neonates did not affect claudin 2 expression, occludin expression, or the transepithelial resistance in rat proximal tubule cells in vitro. In conclusion, there are postnatal maturational changes in tight junction proteins. The factors that cause these maturational changes are unknown but unlikely to be due solely to the maturational increase in thyroid hormone. (Pediatr Res 57: 453-457, 2005)

Abbreviatio
LTA, lotus tetragonolobus lectin
MEM, Minimal Essential Medium

The proximal tubule receives an ultrafiltrate from the glomerulus and reabsorbs two thirds of the ultrafiltrate in a nearly iso-osmotic manner. In addition to active transcellular fluid transport, the proximal tubule reabsorbs solutes via passive diffusion across the paracellular pathway. The early proximal tubule reabsorbs glucose and amino acids and preferentially reabsorbs bicarbonate over chloride ions $(1,2)$, which leaves the luminal fluid delivered to the late proximal tubule with a higher chloride concentration and lower bicarbonate concentration than that in the peritubular plasma $(1,2)$. Passive solute transport is dependent on the gradients that develop between lumen and peritubular capillary and permeability properties of the paracellular pathway.

Approximately two thirds of the filtered chloride is reabsorbed by the adult proximal tubule $(1,3)$. In proximal tubules perfused in vivo and in vitro with a high chloride-low bicarbonate solution simulating late proximal tubular fluid, approximately half of $\mathrm{NaCl}$ transport is active and transcellular and

Received April 13, 2004; accepted August 16, 2004.

Correspondence: Michel Baum, M.D., Department of Pediatrics, UT Southwestern Medical Center, 5323 Harry Hines Boulevard, Dallas, TX 75235-9063; e-mail: Michel.Baum@UTSouthwestern.edu

This work was supported by National Institute of Diabetes and Digestive and Kidney Disease Grant DK-41612 (to M.B.)

DOI: 10.1203/01.PDR.0000151354.07752.9B half is passive and paracellular (3-5). Active $\mathrm{NaCl}$ transport is mediated by the parallel operation of the $\mathrm{Na}+/ \mathrm{H}+$ exchanger and a $\mathrm{Cl}-$ /base exchanger $(3,4)$. Passive $\mathrm{Cl}$ absorption is mediated by diffusion of chloride ions down its concentration gradient generated in the early proximal tubule $(6,7)$. Thus, the permeability properties of the paracellular pathway can affect a significant amount of proximal tubule $\mathrm{NaCl}$ transport.

Furthermore, the permeability properties of the paracellular pathway serve as a barrier to prevent the back diffusion of glucose, amino acids, phosphate, bicarbonate, and other solutes that are in higher concentration in the peritubular fluid than in the lumen of the late proximal tubule. In previous in vitro rabbit microperfusion studies, our laboratory demonstrated that unlike the adult segment, the neonatal proximal tubule was impermeable to chloride ions (8). We also demonstrated that the neonatal proximal tubule had a much higher electrical resistance than the adult segment. We hypothesized and provided evidence that this difference in chloride permeability was due to the maturational change in thyroid hormone levels (4). The tight junction, which determines the paracellular permeability properties of epithelia, is composed of occludin and a family of proteins known as claudins (9-11). Occludin and claudin 2 are known to be expressed in the renal proximal tubule (12-14). The purposes of the present study were to determine whether tight junction proteins change in abundance 
during postnatal renal development and to test our hypothesis that thyroid hormone is responsible for the maturational change in tight junction proteins.

\section{METHODS}

Pregnant Sprague-Dawley rats were received on the 16th day of gestation. The pups stayed with the mother until the day when they were killed. Hyperthyroidism was induced by daily intraperitoneal injections of 3,5,3'-Ltriiodothyronine (T3; Sigma Chemical Co., St. Louis, MO) from day 4 to 8 of life with $10 \mu \mathrm{g} / 100 \mathrm{~g}$ of T3 (4). T3 was dissolved in $0.01 \mathrm{M}$ of $\mathrm{NaOH}$ and sonicated for $10 \mathrm{~min}$ and the $\mathrm{pH}$ was titrated with $\mathrm{HCl}$ to 7.4-8.0 (4). Control neonates and adults were administered vehicle. Neonates were studied on day 8 of life, $2 \mathrm{~h}$ after administration of T3 or vehicle. There were at lease six animals in each group. These studies were approved by the Institutional Review Board of the University of Texas Southwestern Medical Center.

Proximal tubule isolation. Rat proximal tubules were prepared using the same protocol previously used by our laboratory $(15,16)$, according to the method described by others (17-19). Briefly, neonatal and adult rats were killed, and their kidneys were removed and the cortex was dissected, minced, and placed in Kreb's solution $\left(4^{\circ} \mathrm{C}\right)$ that contained (in $\left.\mathrm{mM}\right) 105 \mathrm{NaCl}, 24$ $\mathrm{NaHCO}_{3}, 5 \mathrm{KCl}, 1.5 \mathrm{CaCl}_{2}, 1.0 \mathrm{MgSO}_{4}, 2.0 \mathrm{Na}_{2} \mathrm{PO}_{4}, 5.0$ glucose, 1.0 alanine, 4.0 lactate, 10.0 HEPES, and $0.2 \% \mathrm{BSA}$ adjusted to $300 \mathrm{mOsmol} / \mathrm{kg} \mathrm{H}_{2} 0$ and that was gassed with $95 \% \mathrm{CO}_{2} / 5 \% \mathrm{O}_{2}(\mathrm{pH} 7.4)$. The minced cortex then was incubated in a shaker bath for $45 \mathrm{~min}$ at $37^{\circ} \mathrm{C}$ after $150 \mathrm{mg} / 100 \mathrm{~mL}$ of collagenase was added (Boehringer-Mannheim, Indianapolis, IN). The solution was incubated in a shaker bath at $37^{\circ} \mathrm{C}$ for $35 \mathrm{~min}$. The reaction was arrested by the addition of ice-cold Kreb's solution $\left(4^{\circ} \mathrm{C}\right)$, and the solution was filtered through four layers of gauze. The pellet then was washed three times and resuspended in a 45\% Percoll solution (Pharmacia, Piscataway, NJ) that contained (in mM) $100 \mathrm{NaCl}, 26 \mathrm{NaHCO}_{3}, 3.4 \mathrm{KCl}, 1.2 \mathrm{~K}_{2} \mathrm{HPO}_{4}, 1.2 \mathrm{MgSO}_{4}$, and $2.6 \mathrm{CaCl}_{2}$ and was centrifuged at $14,500 \mathrm{rpm}$ for $30 \mathrm{~min}$ at $4{ }^{\circ} \mathrm{C}$ to separate the proximal tubules (fourth layer) from glomeruli and distal nephron segments. The proximal tubules (at 5-6 $\mathrm{mg}$ of protein $/ \mathrm{mL}$ ) were washed and resuspended in RIPA buffer that contained (in $\mathrm{mM}$ ) $150 \mathrm{NaCl}, 50$ Tris $\mathrm{HCl}, 5$ EDTA, $1 \%$ Triton $\times 100,0.5 \%$ deoxycholic acid, and $0.1 \%$ SDS (pH 7.4). The RIPA buffer contained $100 \mu \mathrm{g} / \mathrm{mL}$ of phenylmethylsulfonyl fluoride, $2 \mu \mathrm{g} / \mathrm{mL}$ of aprotinin, and $2 \mu \mathrm{g} / \mathrm{mL}$ of leupeptin.

SDS-PAGE and immunoblotting. Neonatal, thyroid-treated neonatal and adult proximal tubule proteins $(100 \mu \mathrm{g} / \mathrm{lane})$ were denatured and then separated on a $6 \%$ polyacrylamide gel using SDS-PAGE as previously described $(20,21)$. The proteins were transferred overnight to a polyvinylidene diflouride membrane at $120-140 \mathrm{~mA}$ at $4^{\circ} \mathrm{C}$. The blot was blocked with fresh Blotto [5\% nonfat milk and $0.1 \%$ Tween 20 in PBS ( $\mathrm{pH}$ 7.4)] for $1 \mathrm{~h}$ followed by incubation with primary antibody to mouse occludin and mouse claudin 2 (Zymed Laboratories, San Francisco, CA) at a 1:200 and 1:100 dilution, respectively, overnight at $4^{\circ} \mathrm{C}$

The blot then was washed extensively with Blotto. The secondary antibody, horseradish peroxidase-conjugated donkey anti-rabbit immunoglobulin, was added at 1:10,000 dilution and incubated in room temperature for $1 \mathrm{~h}$. The blot was washed again with Blotto, and enhanced chemiluminescence was used to detect bound antibody (Amersham Life Science). The occludin and claudin 2 protein abundance was quantified using densitometry. Equal loading of samples was confirmed using an antibody to $\beta$-actin at a 1:5000 dilution (Sigma Chemical Co.).

Immunohistochemistry. Tubules were used for immunohistochemistry rather than tissue sections as we had much better staining using the following technique. Kidneys were harvested after whole-body perfusion via left ventricle with $20 \mathrm{~mL}$ of Minimal Essential Medium (MEM; Invitrogen, Carlsbad, CA) followed by $3 \mathrm{~mL}$ of $0.2 \%$ collagenase in MEM. Renal capsules were removed and kidneys were minced to $1-\mathrm{mm}^{3}$ pieces before digestion with $0.2 \%$ collagenase for $30 \mathrm{~min}$ at $37^{\circ} \mathrm{C}$ with gentle shaking. After washing with MEM, tubular fragments were fixed with $95 \%$ alcohol for 30 min followed by acetone fixation for $1 \mathrm{~min}$ at room temperature. Tubules were spotted onto charged glass slides and permeabilized with $1 \%$ paraformaldehyde and $0.05 \%$ Tween 20 for $1 \mathrm{~h}$. After washing with PBS, tubules were blocked with $10 \%$ goat serum and $0.1 \%$ BSA in PBS for 30 min followed by quenching with $0.5 \%$ $\mathrm{NH}_{4} \mathrm{Cl}$ and $0.1 \%$ BSA in PBS for 15 min. Tubules were incubated with anti-claudin 2 at 1:200 dilution or anti-occludin at 1:100 dilution in 10\% goat serum and $0.1 \%$ BSA overnight at $4^{\circ} \mathrm{C}$. After washing with PBS, Alexa Fluor 594 goat anti-rabbit IgG (Molecular Probe, Eugene, OR) diluted at 1:400 in PBS with $0.1 \%$ BSA was added for $40 \mathrm{~min}$ at room temperature. For identifying proximal tubules, the preparation was stained further with FITClabeled lotus tetragonolobus lectin (LTA; Vector Laboratories, Burlingame, CA) at $50 \mu \mathrm{g} / \mathrm{mL}$ in PBS with $0.1 \%$ BSA for $2 \mathrm{~h}$ at room temperature and postfixed with $4 \%$ paraformaldehyde for 5 min before being covered with a glass coverslip in Vectorshield antifade solution (Vector Laboratories). Stained tubules were photographed under epifluorescence illumination using a Zeiss Axioplan microscope (Carl Zeiss Light Microscopy, Gottingen, Germany), and the images were analyzed using OpenLab software (Improvision, Lexington, MA).

Cell Culture and resistance measurements. NRK cells (normal rat proximal tubule cells from American Type Culture Collection) were grown on 12-mm-diameter Snapwell filters (Costar; $0.4-\mu \mathrm{M}$ pore size) in medium that contained equal amounts of MEM and F12 that contained 10\% serum supplemented with $100 \mathrm{U} / \mathrm{mL}$ of penicillin and $100 \mu \mathrm{g} / \mathrm{mL}$ of streptomycin. Confluent monolayers were rendered quiescent by removal of serum $24 \mathrm{~h}$ before study. T3 was prepared in $10^{-2} \mathrm{M}$ of $\mathrm{NaOH}$ that was diluted $10^{5}$-fold with culture medium (final concentration $10^{-7} \mathrm{M}$ ). Control cells were treated with a similar concentration of $\mathrm{NaOH}$.

Transepithelial resistance was measured using an Ussing chamber with a computer controlled voltage/current clamp (Physiologic Instruments, San Diego, CA). At the beginning of each experiment, a Snapwell filter without cells was used to zero the instrument. The apical and basolateral compartments were filled with an ultrafiltrate-like solution that contained $105 \mathrm{mM}$ of $\mathrm{NaCl}, 25$ $\mathrm{NaHCO}_{3}, 10 \mathrm{Na}$ of acetate, $1 \mathrm{mM}$ of $\mathrm{MgSO}_{4}, 2 \mathrm{mM}$ of $\mathrm{Na}_{2} \mathrm{HPO}_{4}, 5 \mathrm{mM}$ of $\mathrm{KCl}, 5 \mathrm{mM}$ of alanine, $8.3 \mathrm{mM}$ of glucose, $2 \mathrm{mM}$ of lactate, $2 \mathrm{mM}$ of glutamine, and $1.2 \mathrm{mM}$ of $\mathrm{CaCl}_{2}$ and was maintained at $37^{\circ} \mathrm{C}$. The solution was continuously bubbled with $95 \% \mathrm{CO}_{2}$ and $5 \% \mathrm{O}_{2}$ and had a $\mathrm{pH}$ of 7.4.

Statistical analysis. Data are reported as the mean \pm SEM. ANOVA, with post hoc Student-Newman-Keuls method, was used to determine statistical significance.

\section{RESULTS}

In the first series of experiments, we examined whether there was a maturational change in occludin and claudin abundance, two proteins that are known to be present in tight junctions of proximal tubules (12-14). There were large changes in the expression of these tight junction proteins during postnatal maturation. Occludin, a tight junction protein with ubiquitous expression, had a dramatic increase in expression with postnatal maturation, as is shown in Figure 1. Claudin 2, a tight junction protein that is known to be expressed in mature proximal tubules, had abundant expression in the neonate but a relative paucity of expression in adult proximal tubules, as shown in Figure 2. We had hypothesized from physiologic data that the developmental increase in thyroid hormone accounted for the increase in paracellular chloride transport and decrease in resistance. To test this hypothesis, we examined the effect of thyroid hormone in neonates using a protocol that resulted in an increase in neonatal chloride permeability (4). As is seen in Figures 1 and 2 administration of thyroid hormone to neonates resulted in no change in the abundance in occludin or claudin 2. In these studies, neonates had a lower serum T3 level than adults $(35.5 \pm 7.7$ versus $90.9 \pm 7.7 \mathrm{ng} / \mathrm{dL} ; p<0.01)$. The T3 level was $1361.2 \pm 687 \mathrm{ng} / \mathrm{dL} 2 \mathrm{~h}$ after thyroid hormone treatment.

We next used immunohistochemistry to examine the expression of claudin 2 and occludin in proximal tubules during maturation. Using proximal tubular epithelial cell marker LTA, which binds to brush border glycoproteins, we identified staining patterns of tight junction proteins claudin 2 and occludin in the proximal tubules. In the neonate, claudin 2 staining was clearly evident at intercellular tight junctions (Fig. 3). This staining pattern is in agreement with the findings of Reyes $e t$ al. (22). Thyroid hormone treatment did not alter the staining pattern of claudin 2 in proximal tubules in neonate. However, in adult rats, most proximal tubules do not have significant claudin 2 staining. In the adult proximal tubules that stained 


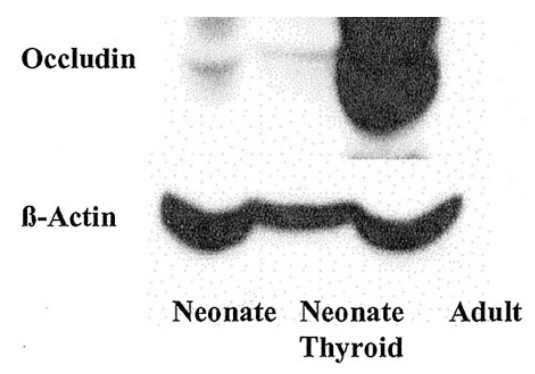

Proximal Tubule Occludin/ $\beta$-Actin Ratio

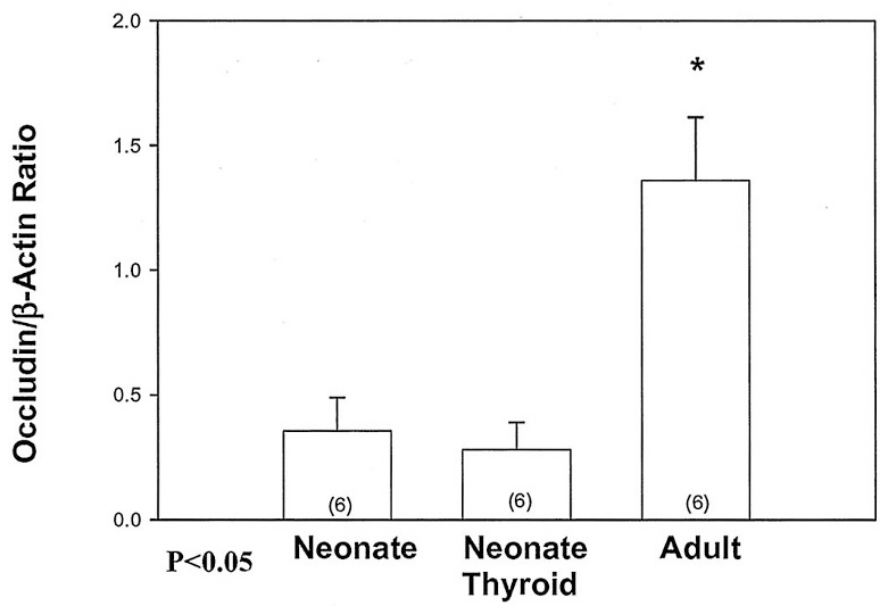

Figure 1. Maturational change in occludin expression. There is a maturational increase in occludin protein expression; however, thyroid hormone administered to neonates had no effect on occludin protein abundance. *Adult value is different from other groups at $p<0.05$.

positive for claudin 2 , the staining intensity was much reduced and appeared discontinuous along the cell borders. However, proximal tubular staining of occludin showed increased expression with age. Occludin was restricted to the apical surface of proximal tubules in neonates that were treated with vehicle or thyroid hormone. Its expression increased in adults, and staining pattern extended to the lateral aspects of the tubules.

We next examined directly whether thyroid hormone affected paracellular resistance by incubating proximal tubule cells with thyroid hormone. As is shown in Figure 4, addition of $10^{-7} \mathrm{M}$ of thyroid hormone for $24 \mathrm{~h}$ did not affect paracellular resistance. Thus, the maturational increase in serum thyroid hormone is unlikely the cause for the developmental change in proximal tubule paracellular resistance.

\section{DISCUSSION}

The tight junction creates the primary permeability barrier to diffusion of solutes across the paracellular pathway. Recently, several protein components of the tight junction have been identified and characterized (9-11). Occludin and claudin proteins are localized to junctional fibrils and are a transmembrane component of tight junctions (23-25). Both occludin and all members of the claudin family have four transmembrane do-
Claudin 2
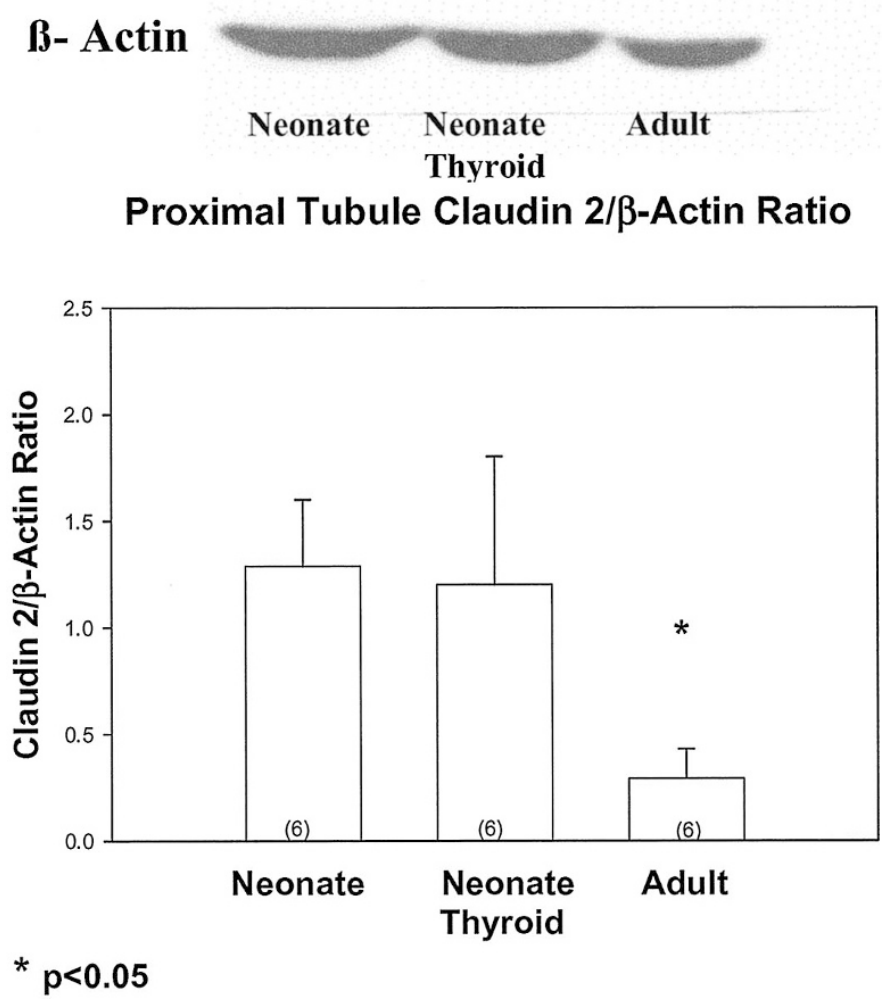

Figure 2. Maturational change in claudin 2 expression. There is a maturational decrease in claudin 2 expression; however, thyroid hormone administered to neonates had no effect on claudin 2 protein abundance. *Adult value is different from other groups at $p<0.05$.

mains and two extracellular loops, which form a seal at the tight junction between neighboring cells $(24,26)$. Occludin and claudin proteins form the tight junction strands or fibrils that are a major factor determining the permeability properties of the paracellular pathway (27-30). The abundance of occludin and the claudin isoforms present are thought to affect the permeability of the paracellular pathway in epithelia $(9,27-32)$. The present study demonstrates for the first time that there are significant developmental changes in claudin and occludin abundance during postnatal maturation that may affect the developmental paracellular permeability properties that occur in the proximal tubule.

The axial gradient with a higher bicarbonate and lower chloride concentration results in the potential for both passive chloride absorption and bicarbonate backflux from the blood into the lumen down the concentration gradients that are generated in the early proximal tubule. We have performed several physiologic studies pointing to a developmental change in paracellular permeability $(4,5,8,33,34)$. Neonatal rabbit proximal tubules have a lower bicarbonate and chloride permeability than that of the adult segment $(8,34)$. Although this would prevent bicarbonate back diffusion, which would favor 


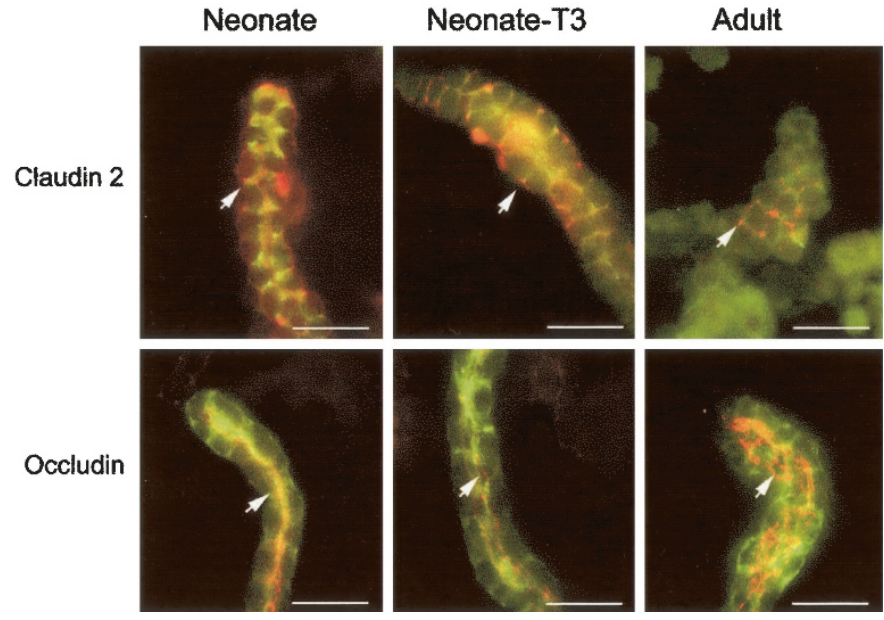

Figure 3. Immunohistochemistry of proximal tubule expression of occludin and claudin 2. Claudin 2 and occludin were present in proximal tubules of neonate and adult rats. Neonates were treated with vehicle or thyroid hormone. (Top) Claudin 2 staining (arrow) in red. (Bottom) Occludin staining (arrow) in red. FITC-labeled LTA shows proximal tubule brush border membranes in green. Magnification: $\times 630$. Bar $=20 \mu \mathrm{M}$.

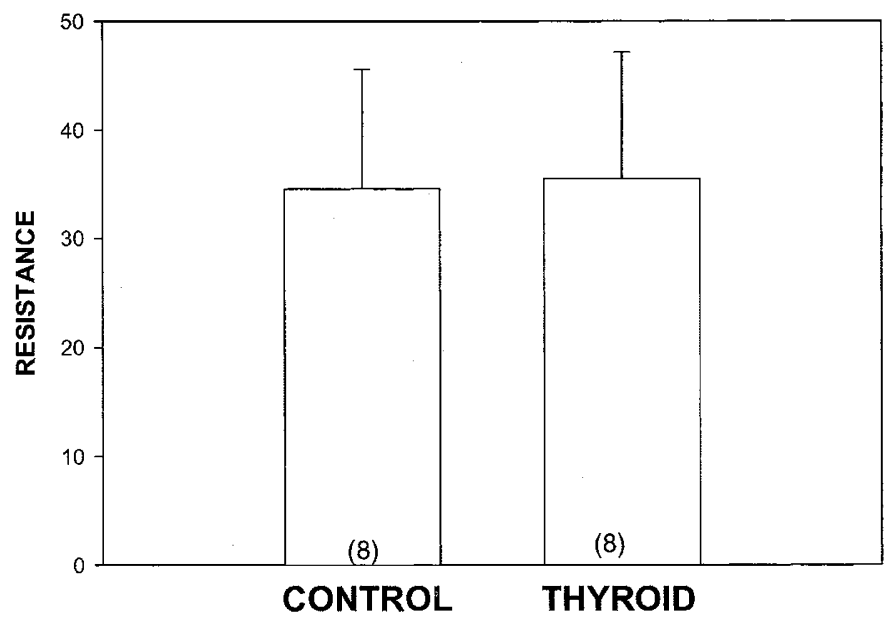

Figure 4. Effect of thyroid hormone on rat proximal tubule cell resistance. NRK cells were rendered quiescent and treated with vehicle or $10^{-7} \mathrm{M}$ of T3 for $24 \mathrm{~h}$. There was no significant difference in resistance between the two groups.

net bicarbonate absorption, the low chloride permeability in the neonatal segment decreases passive chloride absorption.

We recently demonstrated that adult rabbit proximal straight tubule perfused with a late proximal tubular fluid had a $50 \%$ reduction in the rate of volume absorption when active transport was inhibited by $10^{-5} \mathrm{M}$ of bath ouabain $(4,5)$. The remaining half of chloride transport in this segment transport is passive and paracellular (6). In the neonate, the rate of passive chloride transport is not different from zero (8). We examined the permeability properties of neonatal and adult rabbit proximal tubules (8). There were striking differences during postnatal maturation. Neonates had a chloride permeability of zero compared with $10.94 \pm 5.21 \times 10^{-5} \mathrm{~cm} / \mathrm{s}$ in adult proximal tubules, yet mannitol permeability was identical between the two segments. Neonates had a higher $\mathrm{PNa} / \mathrm{PCl}$ and a higher $\mathrm{PHCO}_{3} / \mathrm{PCl}$ than adults. Using current injection and cable analysis, we found that the neonatal proximal tubule had almost twice the resistance than that of the adult segment. Thus, we concluded that there were major changes in the paracellular permeability properties of the neonatal segment compared with the adult. That anion and cation permeabilities were different and mannitol permeability was the same could be explained by the fact that some of the claudin proteins have extracellular loops with charged amino acids that determine the charge permeability of the epithelia $(27,30)$. We hypothesized that thyroid hormone was the most likely candidate causing these changes. We found that administration of thyroid hormone to neonatal rabbits using the same protocol as in the present study resulted in a premature maturation in passive chloride transport from zero to that comparable to the adult segment (5). We also studied adult rabbits that were made hypothyroid by administration of water that contained $0.1 \%$ propylthiouracil. The water was administered to the mothers from $26 \mathrm{~d}$ of gestation and subsequently to the rabbits after weaning until $8 \mathrm{wk}$ of age; the rate of passive volume absorption from a high chloride-late proximal tubular fluid was not different from zero and increased to control adult values with administration of thyroid hormone using the same protocol as in this study (5). The reduction in volume absorption under these conditions in hypothyroid rabbits was consistent with an effect on the paracellular pathway affecting passive $\mathrm{NaCl}$ transport. Although the present study was done in rats because of the availability of antibodies to this species, we demonstrate that the developmental change in neither claudin 2 nor occludin was affected by administration of thyroid hormone to neonates. In addition, thyroid hormone did not affect resistance in proximal tubule cells in vitro, a result consistent with recent findings in the rabbit proximal tubule (35). Thyroid hormone may have a permissive effect rather than a direct effect on tight junction proteins and paracellular resistance.

Previous studies have shown that although thyroid hormone did not augment intestinal sucrase activity in the jejunum of neonates, it had a permissive effect to increase sucrase to adult levels (36). Similarly, thyroid hormone has been shown to increase the sensitivity of the effect of aldosterone to stimulate the Na-K-ATPase in the cortical collecting duct (37). Furthermore, there are now $>20$ claudin isoforms, and it is possible that thyroid hormone affects the maturation of another isoform.

Other studies suggested that thyroid hormone may be involved in the regulation of the permeability of the paracellular pathway $(38-40)$. Thyroid hormone has been shown to decrease the resistance of toad bladders (40). In addition, the bath to lumen flux of ${ }^{36} \mathrm{C}$ and ${ }^{32} \mathrm{P}$ increased with thyroid hormone administration, consistent with a decrease in the paracellular permeability to these anions $(39,40)$. However, passive phosphate and calcium transport across the small intestine was less in rats that received thyroid hormone for $7 \mathrm{~d}$ than in control rats, consistent with a decrease in paracellular movement of these ions with thyroid hormone treatment (38).

In conclusion, we demonstrate for the first time that there are maturational changes that occur in tight junction proteins. These changes in tight junction protein abundance likely play a role in the developmental changes in the physiologic properties of the tight junction, which play an important role in 
passive paracellular chloride transport. This study also adds significant evidence against the hypothesis that the maturational changes that occur in the tight junction are solely the result of the postnatal increase in thyroid hormone levels.

Acknowledgments. We thank Raymond Quigley for suggestions and for reading the manuscript.

\section{REFERENCES}

1. Rector FC Jr 1983 Sodium, bicarbonate, and chloride absorption by the proximal tubule. Am J Physiol 244:F461-F471

2. Liu FY, Cogan MG 1984 Axial heterogeneity in the rat proximal convoluted tubule. I. Bicarbonate, chloride, and water transport. Am J Physiol 247:F816-F821

3. Aronson PS, Giebisch G 1997 Mechanisms of chloride transport in the proximal tubule. Am J Physiol 273:F179-F192

4. Shah M, Quigley R, Baum M 2000 Maturation of proximal straight tubule $\mathrm{NaCl}$ transport: role of thyroid hormone. Am J Physiol 278:F596-F602

5. Shah M, Quigley R, Baum M 1998 Maturation of rabbit proximal straight tubule chloride/base exchange. Am J Physiol 274:F883-F888

6. Baum M, Berry CA 1984 Evidence for neutral transcellular $\mathrm{NaCl}$ transport and neutral basolateral chloride exit in the rabbit convoluted tubule. J Clin Invest 74:205-211

7. Berry CA 1983 Lack of effect of peritubular protein on passive $\mathrm{NaCl}$ transport in the rabbit proximal tubule. J Clin Invest 71:268-281

8. Quigley R, Baum M 2002 Developmental changes in rabbit proximal straight tubule paracellular permeability. Am J Physiol 283:F525-F531

9. Mitic LL, Van Itallie CM, Anderson JM 2000 Molecular physiology and pathophysiology of tight junctions I. Tight junction structure and function: lessons from mutant animals and proteins. Am J Physiol 279:G250-G254

10. Mitic LL, Anderson JM 1998 Molecular architecture of tight junctions. Annu Rey Physiol 60:121-142

11. Denker BM, Nigam SK 1998 Molecular structure and assembly of the tight junction. Am J Physiol 274:F1-F9

12. Gonzalez-Mariscal L, Namorado MC, Martin D, Luna J, Alarcon L, Islas S, Valencia L, Muriel P, Ponce L, Reyes JL 2000 Tight junction proteins ZO-1, ZO-2, and occludin along isolated renal tubules. Kidney Int 57:2386-2402

13. Enck AH, Berger UV, Yu AS 2001 Claudin-2 is selectively expressed in proximal nephron in mouse kidney. Am J Physiol 281:F966-F974

14. Kiuchi-Saishin Y, Gotoh S, Furuse M, Takasuga A, Tano Y, Tsukita S 2002 Differential expression patterns of claudins, tight junction membrane proteins, in mouse nephron segments. J Am Soc Nephrol 13:875-886

15. Sakarcan A, Timmons C, Baum M 1994 Intracellular distribution of cystine in cystine-loaded proximal tubules. Pediatr Res 35:447-450

16. Sakarcan A, Aricheta R, Baum M 1992 Intracellular cystine loading causes proximal tubule respiratory dysfunction: effect of glycine. Pediatr Res 32:710-713

17. Vinay P, Gougoux A, Lemieux G 1981 Isolation of a pure suspension of rat proximal tubules. Am J Physiol 241:F403-F411

18. Weinberg JM, Davis JA, Abarzua M, Kiani T, Kunkel R 1990 Protection by glycine of proximal tubules from injury due to inhibitors of mitochondrial ATP production. Am J Physiol 258:C1127-C1140
19. Weinberg JM, Davis JA, Abarzua M, Smith RK, Kunkel R1990 Ouabain-induced lethal proximal tubule cell injury is prevented by glycine. Am J Physiol 258:F346F355

20. Baum M, Biemesderfer D, Gentry D, Aronson PS 1995 Ontogeny of rabbit renal cortical NHE3 and NHE1: effect of glucocorticoids. Am J Physiol 268:F815-F820

21. Shah M, Gupta N, Dwarakanath V, Moe OW, Baum M 2000 Ontogeny of $\mathrm{Na}+/ \mathrm{H}+$ antiporter activity in rat proximal convoluted tubules. Pediatr Res 48:206-210

22. Reyes JL, Lamas M, Martin D, del Carmen Namorado M, Islas S, Luna J, Tauc M, Gonzalez-Mariscal L 2002 The renal segmental distribution of claudins changes with development. Kidney Int 62:476-487

23. McCarthy KM, Skare IB, Stankewich MC, Furuse M, Tsukita S, Rogers RA, Lynch $\mathrm{RD}$, Schneeberger EE 1996 Occludin is a functional component of the tight junction. J Cell Sci 109:2287-2298

24. Furuse M, Hirase T, Itoh M, Nagafuchi A, Yonemura S, Tsukita S, Tsukita S 1993 Occludin: a novel integral membrane protein localizing at tight junctions. J Cell Biol 123:1777-1788

25. Furuse M, Fujita K, Hiiragi T, Fujimoto K, Tsukita S 1998 Claudin-1 and -2: novel integral membrane proteins localizing at tight junctions with no sequence similarity to occludin. J Cell Biol 141:1539-1550

26. Morita K, Furuse M, Fujimoto K, Tsukita S 1999 Claudin multigene family encoding four-transmembrane domain protein components of tight junction strands. Proc Nat Acad Sci USA 96:511-516

27. Simon DB, Lu Y, Choate KA, Velazquez H, Al Sabban E, Praga M, Casari G, Bettinelli A, Colussi G, Rodriguez-Soriano J, McCredie D, Milford D, Sanjad S, Lifton RP 1999 Paracellin-1, a renal tight junction protein required for paracellular $\mathrm{Mg} 2+$ resorption. Science 285:103-106

28. Colegio OR, Van Itallie C, Rahner C, Anderson JM 2003 Claudin extracellular domains determine paracellular charge selectivity and resistance but not tight junction fibril architecture. Am J Physiol 284:C1346-C1354

29. Colegio OR, Van Itallie CM, McCrea HJ, Rahner C, Anderson JM 2002 Claudins create charge-selective channels in the paracellular pathway between epithelial cells. Am J Physiol 283:C142-C147

30. Van Itallie C, Rahner C, Anderson JM 2001 Regulated expression of claudin-4 decreases paracellular conductance through a selective decrease in sodium permeability. J Clin Invest 107:1319-1327

31. Balda MS, Flores-Maldonado C, Cereijido M, Matter K 2000 Multiple domains of occludin are involved in the regulation of paracellular permeability. J Cell Biochem 78:85-96

32. Tsukita S, Furuse M 2000 Pores in the wall: claudins constitute tight junction strands containing aqueous pores. J Cell Biol 149:13-16

33. Sheu JN, Baum M, Bajaj G, Quigley R 1996 Maturation of rabbit proximal convoluted tubule chloride permeability. Pediatr Res 39:308-312

34. Quigley R, Baum M 1990 Developmental changes in rabbit juxtamedullary proximal convoluted tubule bicarbonate permeability. Pediatr Res 28:663-666

35. Baum M, Quigley R 2004 Thyroid hormone modulates rabbit proximal straight tubule paracellular permeability. Am J Physiol 286:F477-F482

36. Henning SJ 1978 Permissive role of thyroxine in the ontogeny of jejunal sucrase Endocrinology 102:9-15

37. Barlet C, Doucet A 1987 Triiodothyronine enhances renal response to aldosterone in the rabbit collecting tubule. J Clin Invest 79:629-631

38. Noble HM, Matty AJ 1967 The effect of thyroxine on the movement of calcium and inorganic phosphate through the small intestine of the rat. J Endocrinol 37:111-117

39. Matty AJ, Green K 1964 Effect of thyroxine on ion movement in isolated toad bladder. Gen Comp Endocrinol 4:331-338

40. Matty AJ, Green K 1963 Permeability and respiration effects of thyroidal hormones on the isolated bladder of the toad Bufo bufo. J Endocrinol 25:411-425 